\title{
A PERIODIZAÇÃO DA ATIVIDADE HUMANA PARA VYGOTSKI, LEONTIEV E ELKONIN: RUPTURA OU CONTINUIDADE?
}

\author{
Eliete Zanelato' ${ }^{1}$ Sônia da Cunha Urt ${ }^{2}$ \\ 'Doutoranda em Educação pela Universidade Federal de Mato Grosso do Sul (UFMS). Professora da Universidade \\ Federal de Rondônia (UNIR), Campus de Ariquemes, Departamento de Ciências da Educação (DECED). E-mail: \\ elietezan@gmail.com \\ ${ }^{2}$ Doutora em Educação com Pós-doutoramento em Psicologia Educacional pela Universidade Estadual de Campinas \\ (UNICAMP), Pós-doutoramento na Universidade de Alcalá de Henares-ES e na Universidade de Lisboa-PT. Professora \\ titular aposentada e professora pesquisadora Sênior dos Programas de Pós-graduação em Educação e em Psicologia \\ da Universidade Federal de Mato Grosso do Sul (UFMS).
}

\section{RESUMO}

A compreensão do ser humano concreto, não dualista, com bases dialéticas, foi uma preocupação desde a primeira geração da escola psicológica soviética. Os estudos elaborados por essa escola, posteriormente denominada Psicologia Histórico-Cultural, subsidiaram a compreensão de que ao longo da vida, ao realizar atividades para manter sua sobrevivência, o ser humano modifica suas condições externas e internas, isto é, modifica o meio em que vive e suas funções psíquicas. No presente artigo, o objetivo que se insere é a análise da periodização da atividade humana, em Vygotski (1896-1934), Leontiev (1903-1979) e Elkonin (1904-1984), na busca por elementos que interponham continuidades ou rupturas de suas bases. Trata-se de três autores clássicos que dão fundamentação psicológica aos estudos da Pedagogia Histórico-Crítica e que, apesar de pertencerem à mesma escola psicológica, trazem ênfases diferenciadas para pensar a periodização. Para alcançar o objetivo almejado foi realizada uma busca nos textos clássicos desses autores, disponibilizados em português e espanhol, e elaborado um quadro comparativo a partir dos principais períodos: primeira infância, infância, adolescência e vida adulta. A linha de defesa adotada é a de que os estudos da periodização apresentados por Leontiev e Elkonin são uma continuidade dos estudos de Vygotski. Esse último se dedicou mais às questões internas, à elevação do nível de desenvolvimento psíquico, sem deixar de considerá-lo dependente da situação de vida concreta. Já Leontiev e Elkonin exploram mais a influência da atividade social no desenvolvimento psíquico e das relações estabelecidas, tomando como base as categorias de atividade dominante.

Palavras chave: Periodização da Atividade Humana. Psicologia Histórico-Cultural. Vygotski, Leontiev e Elkonin.

\section{THE PERIODIZATION OF HUMAN ACTIVITY FOR VYGOTSKI, LEONTIEV AND ELKONIN: RUPTURE OR CONTINUITY?}

\begin{abstract}
The understanding of the concrete, non-dualistic human being with dialectical bases has been a concern since the first generation of the Soviet psychological school. The studies elaborated by this school, later denominated Historical-Cultural Psychology, subsidized the understanding that throughout the life, when performing activities to maintain its survival, the human being modifies its external and internal conditions, that is, it modifies the environment in which lives and their psychic functions. In the present article, the objective is to analyze the periodization of human activity in Vygotski (1896-1934), Leontiev (1903-1979) and Elkonin (1904-1984), in the search for elements that interpose continuities or ruptures of their bases. These are three classic authors who give psychological foundation to the studies of Historical-Critical Pedagogy and that although they belong to the same psychological school, they bring different emphases
\end{abstract}


to think periodization. In order to reach the desired goal, a search of the classic texts of these authors was made available in Portuguese and Spanish, and a comparative table was drawn from the main periods: early childhood, childhood, adolescence and adult life. The line of defense adopted is that the periodization studies presented by Leontiev and Elkonin are a continuation of Vygotsky's studies. The latter devoted himself more to internal questions, to raising the level of psychic development, while still considering it to be dependent on the situation of concrete life. Already Leontiev and Elkonin further explore the influence of social activity on psychic development and established relationships, based on the categories of dominant activity.

Keywords: Periodization of Human Activity. Historical-Cultural Psychology. Vygotski, Leontiev and Elkonin.

\section{LA PERIODIZACIÓN DE LA ACTIVIDAD HUMANA PARA VYGOTSKI, LEONTIEV Y ELKONIN: RUPTURA O CONTINUIDAD?}

\section{RESUMEN}

La comprensión del ser humano concreto y no dualista con bases dialécticas ha sido una preocupación desde la primera generación de la escuela psicológica soviética. Los estudios elaborados por esa escuela, posteriormente denominada Psicología Histórico-Cultural, subsidiaron la comprensión de que a lo largo de la vida, al realizar actividades para mantener su supervivencia, el ser humano modifica sus condiciones externas e internas, es decir, modifica el medio en que vive y sus funciones psíquicas. En el presente artículo, el objetivo que se inserta es el análisis de la periodización de la actividad humana en Vygotski (1896-1934), Leontiev (1903-1979) y Elkonin (1904-1984), en la búsqueda de elementos que interpongan continuidades o rupturas de sus bases. Se trata de tres autores clásicos que dan fundamentación psicológica a los estudios de la Pedagogía Histórico-Critica y que, a pesar de pertenecer a la misma escuela psicológica, traen énfasis diferenciadas para pensar la periodización. Para lograr el objetivo deseado de una búsqueda se llevó a cabo en los textos clásicos de estos autores, disponible en portugués y español, y se preparó un cuadro comparativo de los principales períodos: la infancia, la niñez, la adolescencia y la edad adulta. La línea de defensa adoptada es la de que los estudios de la periodización presentados por Leontiev y Elkonin son una continuidad de los estudios de Vygotski. Este último se dedicó más a las cuestiones internas, la elevación del nivel de desarrollo psíquico, sin dejar de considerarlo dependiente de la situación de vida concreta. Ya Leontiev y Elkonin exploran aun más la influencia de la actividad social en el desarrollo psíquico y en las relaciones establecidas, tomando como base las categorías de actividad dominante.

Palabras clave: Periodización de la Actividad Humana. Psicología Histórico-Cultural. Vygotski, Leontiev y Elkonin.

\section{INTRODUÇÃO}

Ao longo da vida, o ser humano realiza diversas atividades que possibilitam 0 desenvolvimento de suas funções psíquicas, o que influencia na capacidade do indivíduo de compreender a prática social e a si próprio. Algumas atividades possuem mais influência no desenvolvimento de tais capacidades que outras, dependendo do período de vida em que o indivíduo se encontra e sua realidade concreta, por isso, alguns autores se debruçaram nos estudos da periodização do desenvolvimento humano, dentre eles os clássicos da Psicologia
Histórico-Cultural como Vygotski (1896-1934), Leontiev (1903-1979) e Elkonin (1904-1984).

Periodização, para a Psicologia HistóricoCultural, é o movimento dos períodos pelos quais os seres humanos vivenciam suas relações com o meio e com as outras pessoas ao longo da vida (do nascimento à velhice) e está diretamente atrelado às condições concretas da organização social, ou seja, está atrelado à atividade humana. Leontiev (1978; 2004), fundamentado nos estudos de Vygotski, foi precursor da Teoria da Atividade, e teve seus estudos aprofundados por Elkonin $(1961 ; 1987)$. 
Entretanto, o contexto social da época, que envolveu a primeira e segunda geração da escola psicológica soviética, deixou margens para que alguns autores questionassem se os trabalhos de Leontiev e Elkonin são uma continuidade dos estudos de Vygotski. Podemos citar alguns estudos que caminham nessa perspectiva, como: Yasnitsky (2009), Van Der Veer e Valsiner (1996), González Rey (2007), Toassa (2015a; 2015b; 2016) e Martins (2013).

Duarte (2001), estudioso da Pedagogia Histórico-Crítica, é um dos autores que defende que Leontiev deu continuidade aos estudos de Vygotski. Ele sustenta sua defesa nos fundamentos das teorias elaboradas por Vygotski e Leontiev, ambos autores apoiados na filosofia marxista, ou seja, no Materialismo HistóricoDialético.

Nesse entorno, no presente artigo, o objetivo foi analisar a periodização da atividade humana em Vygotski, Leontiev e Elkonin, na busca por elementos que interponham continuidades ou rupturas de suas bases de fundamentação. Acredita-se que estudar essas bases é fundamental para contribuir na consolidação de um caminho para uma educação escolar como oportunizadora de desenvolvimento psíquico superior, caminho almejado pela Pedagogia Histórico-Crítica.

Para tal, foi realizada uma busca nas obras clássicas desses autores, disponibilizadas em português e espanhol, e foi elaborado um quadro comparativo a partir dos principais períodos estudados por eles, a saber: primeira infância, infância, adolescência e vida adulta. As principais obras foram: Vygotski (1996), Leontiev (2004) e Elkonin (1961).

Como base de análise nos dedicamos, dentro do possível, à explicação dos dados a partir de sua história e sua lógica de desenvolvimento, evitando tomá-los como realidade pronta e acabada. Nesse sentido, os períodos estudados não foram compreendidos como fixos a partir da idade biológica do indivíduo, mas sim, a partir das condições e relações sociais concretas. Como forma de organização da exposição do trabalho, será apresentada, inicialmente, a periodização para cada um dos autores já anunciados e, na sequência, será feita a discussão a partir do quadro comparativo.

\section{A PERIODIZAÇÃO EM VYGOTSKI, LEONTIEV E ELKONIN}

Para Vygotski (1996), determinadas atividades que são principais em uma idade podem se tornar secundárias em outra. Ao realizar sua análise, estudou a periodização da atividade humana com base no desenvolvimento da personalidade, a partir da identificação de períodos de crises. Ele buscou realizar um estudo teórico/científico dos períodos de crises porque, até então, haviam sido realizados apenas estudos empíricos.

Como é característico nos escritos do autor, primeiro fez uma análise dos estudos empíricos já produzidos e, com eles, identificou três peculiaridades do período de crise no desenvolvimento infantil. A primeira se refere, por um lado, às dificuldades em definir o momento de início e de fim das crises, visto que muitas características são imperceptíveis, e por outro, à existência de um ponto culminante que é uma característica comum em todas as idades críticas.

A segunda peculiaridade, identificada nos estudos empíricos, é que neles foram identificadas muitas crianças "difíceis de educar", com a justificativa de que diminui o interesse e a capacidade geral de trabalho nas aulas nessa fase de crises. São visíveis também conflitos com as pessoas com as quais convivem e consigo mesmas, ou seja, conflitos externos e internos.

A terceira peculiaridade é a índole negativa do desenvolvimento, que é destacada pela maioria dos autores estudados por Vygotski (1996). São destacados mais os traços destrutivos que criadores, e consideram que as crianças perdem os interesses que antes orientavam sua atividade, que elas se esvaziam. Até hoje ainda é comum o entendimento da adolescência, por exemplo, com ênfase em caráter negativo, compreendida como fase problemática, como "aborrecência".

Segundo Vygotski (1996), o esquema de crises é comumente assim apresentado pelos autores que estudou: a crise pós-natal gerada pelo nascimento da criança; a crise de um ano, período que demarca a primeira infância; crise dos três anos, ao adentrar na idade pré-escolar; crise dos sete anos, com a entrada na idade escolar; crise dos treze anos, com a chegada da adolescência; e crise dos dezessete anos, com o advento da fase adulta.

$\mathrm{Na}$ concepção vygotskiana, os períodos de crises se alternam com os estáveis e, como o desenvolvimento infantil é um processo dialético, “[...] a passagem de um estágio a outro não é 
feita por via evolutiva, mas revolucionária" (VYGOTSKI, 1996, p. 258). Os períodos não podem ser compreendidos como pré-definidos, mecânicos e estáticos, mas com variações de acordo com as condições históricas e sociais de cada criança, e de acordo com a forma como cada criança reflete, ativa e conscientemente, tais condições.

Vygotski (1996) defende que as crianças são difíceis de educar no período de crise porque o sistema pedagógico utilizado não alcança as mudanças rápidas de sua personalidade. Defende ainda que, para cada aspecto negativo encontrado no período de crise, existe uma mudança positiva (forma nova e superior) na personalidade, que mesmo nos processos críticos se produz atividades construtivas.

$\mathrm{Na}$ crise de treze anos, por exemplo, a queda do desempenho escolar se deve a uma alteração na forma de apropriação de conhecimentos que, antes, era visual-direta e agora passa ser via compreensão e dedução. "A transição para a forma superior de atividade de trabalho intelectual é acompanhada por uma diminuição temporária da capacidade de trabalho [...]" (VYGOTSKY, 1996, p. 259).

O autor propõe um novo esquema de periodização baseado no critério de novas formações psíquicas em cada fase/período (ou idade, como é chamado pelo autor); nele: retira a crise pós-natal, porque antes dela o indivíduo ainda não é um ser social e seus estudos devem ser realizados pela embriologia e não pela Psicologia; retira a crise dos dezessete anos, porque está se dedicando nesse momento apenas ao desenvolvimento infantil; e, considera a maturação sexual como um período estável e não de crise. O novo esquema pode ser apresentado da seguinte forma:

Quadro 1. Esquema de periodização de Vygotski

\begin{tabular}{|c|c|}
\hline Periodo & Idades \\
\hline Primeiro ano & dois meses-um ano \\
\hline Primeira Infância & um ano-três anos \\
\hline Idade pré-escolar & três-sete anos \\
\hline Idade escolar & oito-doze anos \\
\hline Puberdade/adolescência & catorze-dezoito anos \\
\hline
\end{tabular}

Fonte: Vygotski (1996). Org.: Autoras (2019).

Em cada fase novas formações psíquicas se formam na criança e reorganizam sua personalidade. Nas palavras de Vygotski (1996, p. 262), "[...] em cada etapa encontramos sempre uma nova formação central como uma espécie de guia para todo o processo de desenvolvimento que caracteriza a reorganização de toda a personalidade da criança em uma nova base". 0 autor se refere à formação central, porque existem outras novas formações, as parciais, que se agrupam a ela, assim como as formações remanescentes dos períodos anteriores.

$\mathrm{Na}$ infância, a percepção afetiva é a formação central; na idade pré-escolar é o desenvolvimento da memória; e, a partir da idade escolar, é o pensamento, a capacidade de formações de conceitos. Tais formações são compreendidas por Vygotski (1996) como um sistema complexo que se desenvolve com a hierarquia das formações centrais.

Nesse sentido, algumas linhas de desenvolvimento, que eram principais nas etapas anteriores, podem ser acessórias na atual, e viceversa, porque mudam seu significado e o peso na estrutura geral do desenvolvimento. De uma fase a outra ocorre uma reestruturação geral do sistema de consciência e uma mudança de lugar nas linhas, compondo assim novas formações psíquicas (VYGOTSKI, 1996). Nesse processo dinâmico, o autor ressalta a relação entre o todo e as partes no desenvolvimento $e$ as determinações do meio, que, por sua vez, devem ser compreendidas de maneira diferente daquela utilizada no estudo da evolução das espécies. 
No início de cada período de idade ${ }^{1}$ a relação estabelecida entre a criança e o entorno que a rodeia, especialmente 0 social, é totalmente peculiar, específica, única e irrepetível para essa idade. Denominamos essa relação como situação social de desenvolvimento na dita idade. A situação social do desenvolvimento é o ponto de partida para todas as mudanças dinâmicas que se produzem no desenvolvimento durante o período de cada idade. Ela determina plenamente e por inteiro as formas e a trajetória que permitem à criança adquirir novas propriedades de personalidade, uma vez que a realidade social é a verdadeira fonte de desenvolvimento, é a possibilidade de que $o$ social se transforme em individual. Portanto, a primeira questão que devemos resolver, ao estudar a dinâmica de alguma idade, é esclarecer a situação social do desenvolvimento.

(VYGOTSKI, 1996, p. 264, grifo nosso).

A partir da identificação da situação social de cada período, o autor salienta que é preciso esclarecer como surgem e como se desenvolvem, em tais situações sociais, as novas formações. Essas novas formações são resultados/produtos do desenvolvimento de cada período. "As mudanças na consciência da criança se devem a uma forma determinada de sua existência social, própria da idade/período. Por ela, as novas formações maduram sempre ao final de uma idade e não ao começo" (VYGOTSKI, 1996, p. 264).
Com as novas formações ocorrem também mudanças na personalidade do sujeito. Ou seja, ocorrem modificações na situação social, mudam suas funções psíquicas e, com isso, modifica sua forma de compreensão de si mesmo e do mundo que o cerca, o que possibilita mudanças na atuação nesse mundo. Não existe aí uma passividade do sujeito, mas uma postura ativa que permite um processo contínuo de complexificação do desenvolvimento.

De acordo com Vygotski (1996, p. 265), a nova situação do desenvolvimento passa a se converter em ponto de partida para o período seguinte, ocorrendo uma reestruturação da situação social. "A investigação demonstra que essa reestruturação da situação social do desenvolvimento constitui o conteúdo principal das idades críticas". Para ele, essa é a lei fundamental da dinâmica das idades.

Segundo essa lei, as forças
que movem o
desenvolvimento da
criança em uma ou outra
idade, acabam por negar e
destruir a própria base de
desenvolvimento de toda
a idade, determinando,
com a necessidade
interna, o fim da situação
social do
desenvolvimento, o fim da
etapa dada do
desenvolvimento e o
passo ao seguinte e
superior período de idade.
(VYGOTSKI, 1996, p. 265).

A periodização, nesse sentido, opera em uma espiral dialética. Para ilustrar, recorremos a uma figura exposta por Tuleski e Eidt (2016, p. 57) a partir de seus estudos de Vygotski. As autoras demonstram a espiral e explicam que o desenvolvimento da periodização "[...] envolve avanços e recuos, saltos e paralizações. Nesse processo são produzidas e gestadas as atividadesguia de cada período".

\footnotetext{
${ }^{1}$ Vygotski (1996) utiliza o termo período de idade para se referir a fase, etapa ou período. Trata-se das etapas da periodização estabelecidas por ele. Cada idade é ainda dividida em estágios/fases.
} 
Figura 1. Movimento dialético do desenvolvimento infantil

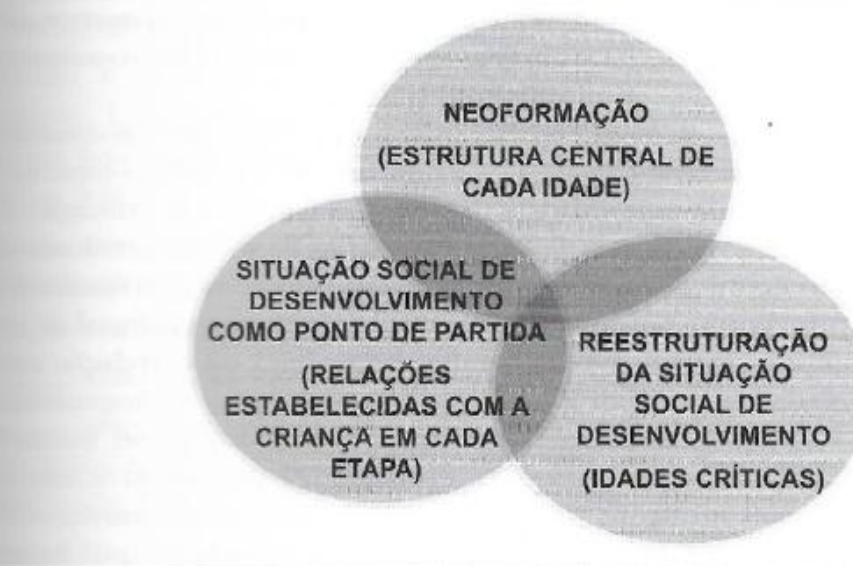

Fonte: Tuleski e Eidt (2016, p. 57).

Como se percebe, o sistema de periodização elaborado por Vygotski (1996) toma por base a dinâmica no processo de desenvolvimento de novas formações psíquicas, sempre com a clara presença das determinações sociais nessas formações, sem, entretanto, ignorar o biológico. A situação social do indivíduo o impulsiona para novos interesses e novas formações psíquicas continuamente. Nessa mesma linha de estudos histórico-culturais, Leontiev (2004) investigou a influência da atividade humana no desenvolvimento do psiquismo e apontou uma periodização com base no conceito de atividade dominante.

Conforme já anunciamos, dentre as diversas atividades humanas, a atividade dominante é aquela que influi de maneira "mais determinante" no desenvolvimento do psiquismo em certos períodos da vida, a saber: o jogo na infância, o estudo durante período escolar até a adolescência e o trabalho a partir da juventude. É por meio dela que o indivíduo se apropria do mundo objetivo e delimita continuamente sua personalidade.

Nesse processo, a posição que o indivíduo ocupa nas relações sociais é o fundamento geral da periodização de Leontiev (2004). Para o autor, a posição que o indivíduo ocupa nas relações sociais está condicionada pelo lugar objetivo que ela ocupa nessas relações. 0 lugar objetivo que ocupa nas relações sociais, por sua vez, promove as condições para o seu desenvolvimento psíquico.

Leontiev (2004, p. 310), ao se referir ao desenvolvimento infantil, destaca que "[...] o que determina diretamente o desenvolvimento do psiquismo da criança é a própria vida, o desenvolvimento dos processos reais desta vida, por outras palavras, o desenvolvimento desta atividade tanto exterior como interior". Nesse intuito, são as condições concretas em que a criança está inserida que impulsionam em maior ou menor grau o seu desenvolvimento psíquico.

O lugar ocupado pela criança mais velha de uma família pobre e que precise ajudar a cuidar dos irmãos mais novos para que os pais ou responsáveis trabalhem, por exemplo, proporcionará condições diferentes de apropriação ao ser comparada a uma criança de classe alta, ou mesmo uma criança que não possua irmãos mais novos. As condições 
concretas mudam e, com isso, mudam as atividades externas e internas.

$\mathrm{Na}$ infância a atividade dominante é o jogo; de acordo com Leontiev (2004, p. 311), tal atividade possui três características:

Primeiramente, é aquela sob a forma da qual aparecem e no interior da qual se diferenciam tipos novos de atividades. Assim, por exemplo, o ensino, no sentido mais restrito do termo, que aparece pela primeira vez na idade pré-escolar, ocorre antes de mais nada no jogo que é a atividade dominante neste estágio do desenvolvimento. A criança começa a aprender jogando. Segundo, a atividade dominante é aquela na qual se formam ou se reorganizam os seus processos psíquicos particulares. É no jogo, por exemplo, que se formam inicialmente os processos de imaginação ativa, e no estudo os processos de raciocínio abstrato. [...] Terceiro, a atividade dominante é aquela de que dependem mais estreitamente as mudanças psicológicas fundamentais da personalidade da criança observadas numa dada etapa do seu desenvolvimento. É no jogo, por exemplo, que a criança de idade préescolar se aproxima das funções sociais e das normas de comportamento que correspondem a certas pessoas [...].

É pelo jogo, atividade dominante na infância, que a criança se apropria do mundo objetivo e desenvolve tanto quanto possível suas funções psíquicas. $O$ jogo de papéis, aquele em que a criança vivencia na brincadeira experiências adultas, possibilita o desenvolvimento de sua personalidade. Ou seja, a atividade dominante é a que dá condições para as principais mudanças psíquicas do sujeito e a prepara para o estágio seguinte.

O jogo, principalmente o jogo de papéis, é uma preparação psíquica para a atividade de estudo e não some imediatamente após a mudança de atividade dominante. Assim como no jogo e no estudo, são geradas as condições para a atividade do trabalho. Não existe uma data para a alteração da atividade dominante, o jogo, por exemplo, vai se tornando cada vez mais complexo e se mantém ao longo de toda a vida.

Para Leontiev (2004), são as condições históricas concretas que influenciam no conteúdo da atividade, e este, por sua vez, influencia na mudança do estágio de desenvolvimento, não a idade da criança. Segundo o autor, "[...] o lugar anteriormente ocupado pela criança no mundo das relações humanas que a rodeia é conscientizado por ela como não correspondendo às suas possibilidades. E daí que se esforce por modificá-lo" (LEONTIEV, 2004, p. 313).

Com base nas apropriações já realizadas, se abrem inúmeras possibilidades para a criança, possibilidades essas que extrapolam o modo de vida anterior, com isso sua atividade precisa se reorganizar passando a um novo estágio do desenvolvimento psíquico, passando por saltos qualitativos (LEONTIEV, 2004). Assim, a criança precisa superar sua infância e incorporar os conteúdos da adolescência; isso ocorre à medida que ela vai se apropriando de elementos da vida concreta.

O autor (LEONTIEV, 2004) aponta a educação dirigida como uma das principais responsáveis pela mudança do tipo dominante de atividade, uma vez que ela conduz a uma necessidade interior nova a partir de novas tarefas, cada vez mais complexas, o que gera necessidade de reorganização. Ao adentrar na escola, aos poucos a atividade dominante passa ser o estudo. Nesse período, que vai até a adolescência, é pelo estudo que ocorrem as principais relações com a realidade concreta e em seguida, pelo trabalho.

Outro autor que estudou a periodização das atividades humanas foi Elkonin (1961); ele teve como base os estudos de Leontiev, manteve a atividade dominante como categoria de diferenciação de período e esmiuçou cada uma delas. Apresentamos no quadro abaixo sua sistematização. 
Quadro 2. Sistematização da periodização da atividade humana por Elkonin

\begin{tabular}{|l|l|}
\hline \multicolumn{1}{|c|}{ Período } & \multicolumn{1}{c|}{ Atividade dominante e relações } \\
\hline Primeira infância & $\begin{array}{l}\text { Atividade de comunicação emocional direta (relação criança- } \\
\text { adulto) }\end{array}$ \\
\cline { 2 - 2 } & $\begin{array}{l}\text { Manipulação objetal (uso social do objeto; relação criança- } \\
\text { objeto) }\end{array}$ \\
\hline Infância & Jogo de papéis \\
\cline { 2 - 2 } & Atividade de estudo (idade escolar primária) \\
\hline Adolescência/juventude & Atividade de estudo (idade escolar secundária ou média) \\
\cline { 2 - 2 } & $\begin{array}{l}\text { Atividade de estudo voltado para o trabalho (idade escolar } \\
\text { juvenil ou preparatória) }\end{array}$ \\
\cline { 2 - 2 } & Relação adolescente com seus pares \\
\hline Idade adulta & Trabalho \\
\hline
\end{tabular}

Fonte: Elkonin (1961). Org.: Autoras (2019).

Como se pode perceber no quadro acima, o autor sistematizou a periodização das atividades humanas. Para ele, tal sistematização é um plano/projeto de desenvolvimento humano que tem como atividade fulcral a atividade de trabalho (atividade consciente). 0 desenvolvimento psíquico, dependendo de como for o processo, alcança seus níveis mais altos de capacidades na atividade de trabalho.

A defesa de Elkonin (1961), assim como a de Vygotski (1996) e de Leontiev (2004), já apresentadas nesse tópico, é a de que são as condições concretas de vida, incluindo as condições de educação, de meio ambiente, de influência direta dos adultos, que determinam o desenvolvimento psíquico.

Inicialmente, a psique infantil, entendida como produto da atividade do cérebro, está ligada diretamente ao sistema nervoso, mas, com o passar do tempo, à medida que as influências sociais são refletidas ativamente pelas crianças, tais influências passam a ser decisivas no processo de desenvolvimento psíquico (ELKONIN, 1961). Dessa maneira, quanto mais próximo ao nascimento, maior a predominância biológica no psiquismo e, inversamente, quanto mais distantes do nascimento, maior a predominância do social.

Na primeira infância, inicialmente, toda a organização da criança é direcionada pelos adultos, são eles os portadores da experiência social a ser transmitida. Com o passar do tempo as crianças vão tendo suas experiências, estas vão se ampliando, vão se tornando mais ricas com o avançar de suas idades (ELKONIN, 1961). Isso não se dá de maneira mecânica, mas em um processo de apropriação e de reflexão constante da criança, em que ela conserva suas aquisições e as usa para conquistar novas formações. A criança nunca é apenas
um objeto de influência
que reflete passivamente
tudo o que acontece ao
seu redor, mas ela sempre
tem uma atitude ativa em
relação a qualquer
influência que recebe de
fora. Ela sempre se
encontra em um ou outro 
nível de desenvolvimento com o qual deve contar para qualquer influência atual sobre ele (ELKONIN, 1961, p. 498).

Um nível de desenvolvimento é utilizado como base para outro e encontra seu ápice na atividade de trabalho. Entretanto, para isso, o autor destaca o papel direto do ensino e da educação, considerando-os indispensáveis. Mesmo antes de aprender a falar a criança começa a assimilar a experiência social, principalmente manipulando objetos. Tais objetos possuem uma função social, são carregados de experiências e significados, o que permite à criança aprender novos conhecimentos e desenvolver novas capacidades.

Como resultado da apropriação de conhecimentos e capacidades cada vez mais complexas está a elevação do desenvolvimento da criança a um nível mais avançado, o que the possibilita novas apropriações. Em um novo nível, qualitativamente superior, a criança conseguirá gradativamente se utilizar dos jogos de papéis ${ }^{2}$, por exemplo, como instrumento principal de novas apropriações da experiência social.

$\mathrm{Na}$ idade pré-escolar, a criança já adquiriu certa independência para algumas atividades e ampliou seu vocabulário e sua capacidade de utilizar a linguagem. Se amplia também, segundo Elkonin (1961) o interesse em participar da vida e atividade dos adultos, mas, como ainda não podem efetivamente, a vivenciam através dos jogos de papeis.

Uma criança não pode ainda ser professora como sua mãe, mas no jogo ela pode assumir e desempenhar essa função. Nesse jogo, costumam ser respeitadas as regras estabelecidas socialmente para essa função. Ela assume o papel de professora, não pode agir como um aluno/criança, essa não é uma atitude aceita nas regras do jogo ao reproduzir a atividade dos adultos. Ao reproduzir tais atividades, a criança se apropria do conteúdo do trabalho de professora e percebe as relações sociais que se criam na vida concreta.

Segundo Elkonin (1961, p. 520), “[...] os novos tipos de atividade (formas mais complicadas de jogo, de desenho, de modelagem, de construção e de formas elementares de

\footnotetext{
${ }^{2}$ Adotamos o termo jogos de papéis, que Elkonin (1961) também chama de jogos ação ou jogos de argumentos. Todos os termos se referem ao jogo realizado principalmente no período pré-escolar.
}

trabalho) servem de base para a reconstrução de toda a atividade mental da criança". Ao ampliar suas atividades, ampliam-se também suas possibilidades de elaborações, de generalizações, de compreensão de mundo.

O período escolar é dividido por Elkonin (1961) em três momentos, a saber: idade escolar

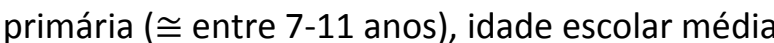

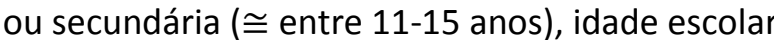

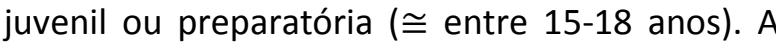
primária é marcada pela entrada da criança na escola $^{3}$, o que gera uma mudança em sua situação social e no conteúdo de sua atividade.

Por mais que algumas escolas priorizem a alfabetização desde o período pré-escolar, a exigência socialmente estabelecida é para que ela aconteça no primeiro ano do Ensino Fundamental. Com isso, família e escola consideram o estudo como uma atividade séria, o que impulsiona as crianças a terem mais responsabilidades para cumprir as exigências. Todo o contexto muda; por exemplo, as pessoas da casa precisam manter silêncio para que a criança faça suas tarefas; a compra de um livro, que antes era dispensável, por ser considerado um brinquedo, agora passa ser uma ferramenta que auxilia na alfabetização.

No decorrer da idade escolar primária o jogo se mantém e continua influenciando no desenvolvimento psíquico da criança, mas deixa de ser a atividade dominante, cedendo esse lugar ao estudo, conforme expõe Elkonin (1961). O interesse por jogos que exigem capacidades mais intelectuais se amplia. Com relação à atividade de trabalho, que geralmente está ligada ao ambiente familiar, esta também influencia no desenvolvimento psíquico, se torna importante aliada para o estudo.

As investigações têm
demonstrado que os
escolares que na família
cumprem obrigações de
trabalho, estudam melhor
que os que estão livres de
tarefas domésticas
(Slavina). Isto se explica
porque o estudo também
é um trabalho que exige
da criança qualidades
determinadas da
personalidade:
sentimentos de dever e de

\footnotetext{
${ }^{3}$ Com base no contexto de seus escritos e trazendo para a realidade atual no Brasil, o autor se refere à entrada da criança no primeiro ano do Ensino Fundamental.
} 
responsabilidade, saber subordinar sua conduta às tarefas sociais, vencer as dificuldades, organizar a atividade etc. Essas qualidades se fazem traços constantes da personalidade se a vida da criança, na escola e na família, está organizada como é necessário para educar essas qualidades. (ELKONIN, 1961, p. 529).

As tarefas, ou não, que a criança realiza podem alterar seu grau de desenvolvimento. Dragunova (1980) diz que pessoas da mesma idade cronológica podem ter variações em seu nível de desenvolvimento devido às circunstâncias da vida, que podem frear ou acelerar o processo de incorporar os traços adultos. Para o autor, situações que podem tardar o desenvolvimento, por exemplo, são aquelas em que os adultos não atribuem tarefas às crianças, deixando-as livres para apenas estudar, ou aquelas em que os adultos superprotegem as crianças, evitando que vivenciem experiências de preocupações e aflições. Da mesma forma, o excesso de atribuições (domésticas ou não) e vivências conflitivas também podem acelerar a aquisição de traços adultos na criança.

O jogo, o estudo e o trabalho são atividades dos indivíduos que exercem influência em seu desenvolvimento psíquico, entretanto, em determinados períodos da vida, existem os que são dominantes. Elkonin (1987, p. 108) reforça que "[...] cada etapa do desenvolvimento psíquico se caracteriza por uma relação determinada, dominante da etapa dada da criança frente à realidade, por um tipo determinado, dominante de atividade".

A linguagem é destacada em todas as etapas da periodização, por instrumentalizar o processo de apropriação, o que impulsiona o desenvolvimento psíquico. O reflexo consciente e a autorregulação da conduta são mediatizados pelo processo de atividade humana, são resultados da atividade. Duarte $(2001$, p. 164), destaca que "[...] a atividade humana é social e, portanto, sempre mediatizada pelas relações sociais e pela linguagem. Por sua vez, a linguagem só pode existir, na concepção de Marx, como um elemento integrante da prática social, produzido e reproduzido no interior dessa prática".
$\mathrm{Na}$ idade escolar primária, com a apropriação da linguagem escrita, aumentam-se as exigências de atenção, de percepção, de fixação e manutenção de conhecimentos gradativamente mais complexos, amplia-se o desenvolvimento de operações mentais (ELKONIN, 1961). O autor chama a atenção, reincidentemente, para o papel do professor no direcionamento desse processo de aquisição de conhecimentos visando o desenvolvimento psíquico, sendo seu foco constante o caráter da orientação da criança frente à realidade.

Ao se apropriar da linguagem escrita a criança desenvolve novas capacidades cognitivas. Não apenas aprende a escrever palavras, mas também desenvolve novas condições de pensamento e, quanto mais palavras aprende, mais possibilidades de pensamento se instalam. 0 ensino escolar gradativamente permite a formação de um sistema de conceitos, via ensino de distintas formas de raciocínio lógico.

A idade escolar secundária ou média, abarca o período da adolescência e permanece com a atividade principal de estudo. Nesse período, segundo Elkonin (1961, p. 536), o adolescente já ampliou suas capacidades físicas, intelectuais, volitivas e morais, com isso se "[...] criam as premissas necessárias para que mude fundamentalmente a situação do adolescente na sociedade que o rodeia". São exigidos dele maior independência e responsabilidade, se ampliam os interesses cognitivos e os círculos sociais, ocorre também sua maturação sexual.

Durante a adolescência e a juventude, com a ampliação da independência e do círculo social, além da atividade de estudo, as relações com seus pares são colocadas por Elkonin (1961) como elementos importantes para a formação de sua personalidade. Torna-se um período de constante análise do comportamento e dos valores expressos pelos colegas e pelos adultos que os rodeiam, na busca por modelos a seguir.

Segundo Elkonin (1987), no decorrer do desenvolvimento existem períodos em que predominam as relações entre as pessoas e outros em que predominam as relações com os objetos de conhecimento. $\mathrm{Na}$ adolescência essas relações são evidenciadas na comunicação íntima-pessoal e na atividade de estudo.

À medida que a idade avança, que se ampliam as apropriações e que os níveis de desenvolvimento psíquico se tornam mais elevados, aumenta o seu grau de responsabilidade perante a sociedade, e os 
interesses e motivos vão se direcionando para a atividade de trabalho predominantemente. Aos poucos o estudo vai sendo visualizado como uma preparação para o trabalho atual ou futuro.

Já na idade adulta, ainda que se realize as atividades de jogo e estudo, a dominante é o trabalho. Para uma melhor compreensão da sistematização da periodização elaborada pelos autores aqui utilizados, apresentamos a seguir um quadro comparativo. A principal base exposta por Vygotski (1996) foi o desenvolvimento de novas formações psíquicas, a de Leontiev (2004) e Elkonin (1961) foi a atividade dominante e, no caso do último autor, o caráter de orientação do sujeito, as relações.

Quadro 3. Comparativo entre a sistematização da periodização de Vygotski, Leontiev e Elkonin

\begin{tabular}{|c|c|c|c|}
\hline Período & $\begin{array}{l}\text { Vygotski (1996) } \\
\text { Delimitado pelo período de } \\
\text { crises - desenvolvimento de } \\
\text { novas formações psíquicas }\end{array}$ & $\begin{array}{l}\text { Leontiev (2004) } \\
\text { Delimitado pela } \\
\text { Atividade } \\
\text { dominante }\end{array}$ & $\begin{array}{l}\text { Elkonin }(1961,1987) \\
\text { Aprofundamento dos estudos } \\
\text { de Vygotski e Leontiev - } \\
\text { caráter de orientação do } \\
\text { sujeito }\end{array}$ \\
\hline \multirow{2}{*}{$\begin{array}{l}\text { Primeira } \\
\text { Infância }\end{array}$} & $\begin{array}{l}\text { Primeiro ano (dois meses-um } \\
\text { ano). }\end{array}$ & \multirow{2}{*}{ Jogo } & $\begin{array}{l}\text { Atividade de comunicação } \\
\text { emocional direta. }\end{array}$ \\
\hline & $\begin{array}{l}\text { Primeira Infância (um ano- } \\
\text { três anos). }\end{array}$ & & $\begin{array}{l}\text { Manipulação objetal (uso } \\
\text { social do objeto). }\end{array}$ \\
\hline \multirow[b]{2}{*}{ Infância } & $\begin{array}{l}\text { Idade pré-escolar (três-sete } \\
\text { anos). }\end{array}$ & \multirow{2}{*}{$\begin{array}{l}\text { Jogo } \\
\text { Estudo (primeira } \\
\text { etapa). }\end{array}$} & Jogo de papéis. \\
\hline & $\begin{array}{l}\text { anos). } \\
\text { Idade escolar (oito-doze } \\
\text { anos). }\end{array}$ & & $\begin{array}{l}\text { Atividade de estudo (idade } \\
\text { escolar primária). }\end{array}$ \\
\hline \multirow{3}{*}{ Adolescência } & \multirow{3}{*}{$\begin{array}{l}\text { Puberdade/adolescência } \\
\text { (catorze-dezoito anos). }\end{array}$} & \multirow{3}{*}{$\begin{array}{l}\text { Estudo (segunda } \\
\text { e terceira etapas). } \\
\text { Relacionadas as } \\
\text { mudanças de } \\
\text { interesses } \\
\text { principais. }\end{array}$} & $\begin{array}{l}\text { Atividade de estudo (idade } \\
\text { escolar secundária ou média). }\end{array}$ \\
\hline & & & $\begin{array}{l}\text { Atividade de estudo voltado } \\
\text { para o trabalho (idade escolar } \\
\text { juvenil ou preparatória). }\end{array}$ \\
\hline & & & $\begin{array}{l}\text { Relação adolescente com seus } \\
\text { pares (modelos de adulto). }\end{array}$ \\
\hline $\begin{array}{l}\text { Idade Vida } \\
\text { Adulta }\end{array}$ & Não especificado & Trabalho & Trabalho \\
\hline
\end{tabular}

Org.: Autoras (2019).

Ao observar o quadro, podemos perceber que não existe uma ruptura entre as sistematizações elaboradas pelos autores, mas uma complementação. Vygotski (1996) se dedica mais às questões internas, à elevação do nível de desenvolvimento; entretanto, reafirmou diversas vezes a dependência da situação de vida concreta, enfatizou que a realidade social é a verdadeira fonte de desenvolvimento. Leontiev (2004) e Elkonin (1961) exploram mais a influência da atividade social no desenvolvimento psíquico e das relações estabelecidas, tomando como base as categorias de atividade dominante.
Elkonin (1987) valoriza os estudos de Vygotski sobre a periodização e diz que esses precisam ser conservados e atualizados com base nos conhecimentos contemporâneos sobre o desenvolvimento psíquico infantil; cita, dentre eles, os estudos de Leontiev e de Rubinstein sobre atividades dominantes e sua relação com o desenvolvimento da personalidade. Assim como os demais autores supracitados, Elkonin (1987) defende a compreensão do desenvolvimento psíquico infantil como um processo integral.

No quadro é possível perceber que, em todos os períodos, Elkonin intercala atividades dominantes, voltadas à relação do sujeito com 
outras pessoas, com as relações do sujeito com os objetos de conhecimento a serem apropriados. Ele explica:

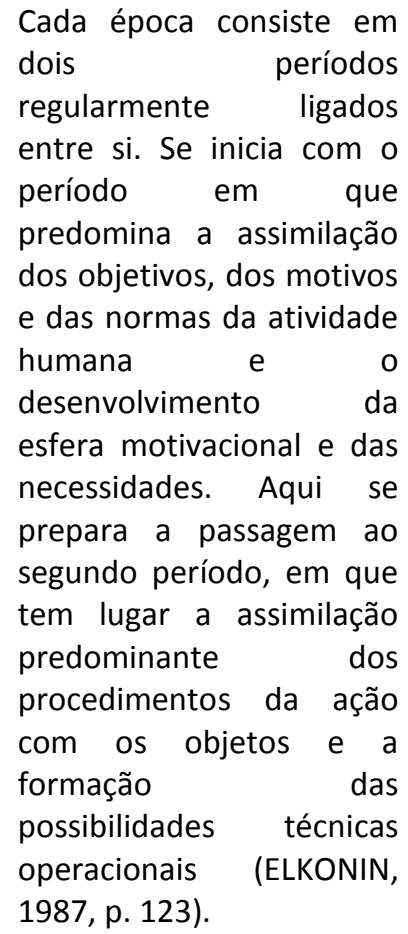

É possível verificar que, tanto em relação a Vygotski e Leontiev, como em relação a esses dois autores com Elkonin, existe um caráter de continuidade e não de ruptura. Em algumas citações diretas do texto, ficou explícita a concordância entre os autores: todos concordam com as neoformações psíquicas no decorrer da periodização das atividades humanas, todos concordam que existem momentos de mudanças qualitativas nas formações psíquicas, concordam que as mudanças no desenvolvimento psíquico são produções sistêmicas decorrentes da prática social e que a linguagem possui uma função ímpar nesse processo.

\section{CONSIDERAÇÕES FINAIS}

Com o propósito de analisar a periodização da atividade humana em Vygotski, Leontiev e Elkonin, na busca por elementos que interponham continuidades ou rupturas de suas bases, nos deleitamos em obras clássicas desses autores. Foi possível expor cada compreensão de periodização e elaborar um quadro comparativo dos três autores a partir do estabelecimento dos seguintes períodos: primeira infância, infância, adolescência e vida adulta.

Pelo exposto, é possível perceber que Vygotski (1996) se dedicou mais ao aprofundamento das neoformações psíquicas formadas ao final de cada período de crises, sem nunca dispensar a influência da prática social nesse processo; inclusive chama as mudanças ocorridas de situação social do desenvolvimento e as considera sempre como ponto de partida para o período seguinte.

Leontiev (2004) investiga com maior empenho a atividade humana e suas condições concretas que possibilitam o desenvolvimento psíquico. Para ele, o jogo, o estudo e o trabalho são as atividades dominantes e é por meio delas que os indivíduos se apropriam do mundo e formam sua personalidade. Elkonin (1961), por sua vez, dá continuidade e aprofunda os estudos de Leontiev, acrescentando que, ao desenvolver as atividades, em todas as etapas, ora predominam as relações entre as pessoas, ora predominam as relações com o objeto de conhecimento.

Pelo presente estudo é possível concordar com Duarte (2001), que existe continuidade entre Vygotski e Leontiev, uma vez que ambos estão fundamentados no Materialismo Histórico-Dialético e compreendem a atividade humana como promotora de desenvolvimento psíquico. Acrescentamos que os três autores cumprem o almejado pela escola psicológica soviética de construção de uma teoria que supere a visão dualista do ser humano.

Os autores consideram o desenvolvimento do psiquismo humano a partir das relações concretas, o que inclui a apropriação, via linguagem, da produção lógica e histórica das gerações anteriores; e que essas apropriações oportunizam novas possibilidades de objetivações humanas, ou seja, oportunizam novas relações e novos objetos. Esses fundamentos deram base para a formulação da Pedagogia Histórico-Crítica.

\section{AGRADECIMENTOS}

Agradecemos à CAPES e à FAPERO pelo auxílio financeiro disponibilizado ao presente estudo.

As autoras declaram não haver qualquer potencial conflito de interesse que possa interferir na imparcialidade deste trabalho científico.

\section{REFERÊNCIAS}

DRAGUNOVA, T. V. Características psicológicas del adolescente. In: PETROVSKI, A. Psicología evolutiva y pedagógica. Moscou, Ru: Editorial Progreso, 1980. p. 119-169. 
DUARTE, N. Vigotski e o "aprender a aprender": Crítica às Apropriações Neoliberais e PósModernas da Teoria Vigotskiana. Campinas: Autores Associados, 2001. (Coleção Educação contemporânea).

ELKONIN, D. B. Desarrollo Psíquico de los Escolares. In: SMIRNOV, A. A. (redactor jefe); LEONTIEV, A. N.; TIEPLOV, B. M. (Orgs.). Psicologia. Cuba: Imprensa Nacional de Cuba, 1961. p. 553-559.

ELKONIN, D. B. Sobre el problema de la periodización del desarrollo psíquico en la infancia. In: DAVIDOV, V.; SHUARE, M. (Orgs.). La psicología evolutiva y pedagógica en la URSS: Antología. Moscou: Editorial Progresso, 1987. p. 104-124.

GONZÁLEZ REY, F. L. As categorias de sentido, sentido pessoal e sentido subjetivo: sua evolução e diferenciação na teoria histórico-cultural. Psicologia da Educação, PUC, São Paulo, n. 24, p. 155-179, 2007.

LEONTIEV, A. N. Actividad, Conciencia y Personalidad. Buenos Aires, AG: Ciências del Hombre, 1978.

LEONTIEV, A. N. Desenvolvimento do Psiquismo. São Paulo: Moraes, 2004.

MARTINS, J. B. Apontamentos sobre a relação Vigotski e Leontiev: A "troika”, ela existiu? Dubna Psychological Journal, Dubna, Moscou, Rússia, v. 1, p. 71-83, 2013.

TOASSA, G. "Atrás da consciência, está a vida": o afastamento teórico Leontiev-Vigotski na dinâmica dos círculos vigotskianos. Educação \& Sociedade, Campinas, v. 37 , n. 135 , p. $445-462$, abr.-jun., 2016. Disponível em: <http://www.scielo.br/pdf/es/v37n135/16784626-es-37-135-00445.pdf>. Acesso em: 10 set. $2018 . \quad$ https://doi.org/10.1590/ES0101$\underline{73302016144457 .}$

TOASSA, G. Is there a "Vygotskian Materialism"? Ontological and epistemological concerns for a contemporary Marxist Psychology (Part l). Revista PsyAnima, Dubna, Moscou, Rússia, n. 3, p. 66-80, 2015a. Disponível em: <http://psyanima.ru/issues/issues-2015/32015/index.html>. Acesso em: 02 ago. 2018.
TOASSA, G. Is there a "Vygotskian Materialism"? Ontological and epistemological concerns for a contemporary Marxist Psychology (Part II). Revista PsyAnima, Dubna, Moscou, Rússia, n. 3, p. 81-93, 2015b. Disponível em: <http://psyanima.ru/issues/issues-2015/32015/index.html>. Acesso em: 02 ago. 2018.

TULESKI, S. C.; EIDT, N. M. A periodização do desenvolvimento psíquico: atividade dominante e a formação das funções psíquicas superiores. In: MARTINS, L. M.; ABRANTES, A. A.; FACCI, M. G. D. (Orgs.). Periodização histórico-cultural do desenvolvimento psíquico: do nascimento à velhice. Campinas: Autores Associados, 2016. p. 35-62.

VAN DER VEER, R.; VALSINER, J. Vygotsky: uma síntese. Trad. C. C. Bartalotti. São Paulo: Unimarco; Loyola, 1996.

VYGOTSKI, L. S. Obras Escogidas. Madrid, ES: Visor Distribuciones, 1996. (Tomo IV).

YASNITSKY, A. Vygotsky circle during the decade of 1931-1941: toward an integrative science of mind, brain, and education. These. Department of Curriculum, Teaching and Learning, Ontario Institute for Studies in Education. University of Toronto, Canada, 2009. 